\title{
Bactericidal and immunomodulatory properties of magnetic nanoparticles functionalized by I,4-dihydropyridines
}

This article was published in the following Dove Press journal: International Journal of Nanomedicine

\section{Katarzyna Niemirowicz- Laskowska' \\ Katarzyna Głuszek' \\ Ewelina Piktel' \\ Karlis Pajuste ${ }^{2}$ \\ Bonita Durnaś ${ }^{3}$ \\ Grzegorz Król ${ }^{3}$ \\ Agnieszka Z Wilczewska ${ }^{4}$ \\ Paul A Janmey ${ }^{5}$ \\ Aiva Plotniece 2 \\ Robert Bucki ${ }^{1}$}

'Department of Microbiological and Nanobiomedical Engineering, Medical University of Bialystok, Bialystok, Poland; 'Laboratory of Membrane Active Compounds and $\beta$-Diketones, Latvian Institute of Organic Synthesis, Riga, Latvia; ${ }^{3}$ Department of Microbiology and Immunology, The Faculty of Health Sciences of the Jan Kochanowski University in Kielce, Kielce, ${ }^{4}$ Institute of Chemistry, University of Bialystok, Białystok. Poland; ${ }^{5}$ Department of Physiology, Institute for Medicine and Engineering, University of Pennsylvania,

Philadelphia, PA, USA
Correspondence: Robert Bucki Department of Microbiological and Nanobiomedical Engineering, Medical University of Bialystok, Mickiewicza 2c, Bialystok 15-222, Poland

Tel +48 857485493

Fax +48 857485416

Email buckirobert@gmail.com
Background: 1,4-Dihydropyridine (1,4-DHP) and its derivatives are well-known calcium channel blockers with antiarrhythmic and antihypertensive activities. These compounds exhibit pleiotropic effects including antimicrobial activities that rely on their positive charge and amphipathic nature. Use of magnetic nanoparticles (MNPs) as carriers of 1,4-DHP modulates their properties and enables improved formulations with higher efficacy and less toxicity.

Methods: In this study, the antimicrobial and immunomodulatory activities of novel 1,4-DHP derivatives in free form and immobilized on MNPs were determined by evaluating pathogen outgrowth and proinflammatory cytokine release in experimental settings that involve incubation of various 1,4-DHPs with clinical isolates of bacteria or fungi as well as mammalian cell culture models.

Results: Conventional immobilization of 1,4-DHP on aminosilane-coated MNPs markedly enhances their antimicrobial activity compared to nonimmobilized molecules, in part because of the higher affinity of these nanosystems for bacterial cell wall components in the presence of human body fluids.

Conclusion: Optimized nanosystems are characterized by improved biocompatibility and higher anti-inflammatory properties that provide new opportunities for the therapy of infectious diseases.

Keywords: magnetic nanoparticles, 1,4-dihydropyridine, antibacterial, antifungal, immunomodulatory properties

\section{Introduction}

In the 19th century, Arthur Hantzsch described the synthesis of 1,4-dihydropyridine (1,4-DHP) based on multicomponent reactions using $\beta$-ketoesters, amines, and aldehydes. Many modifications of the Hantzsch method, including green chemistry reactions, have been reported. ${ }^{1,2}$ For clinical practice, dihydropyridine (DHP) derivatives were introduced in 1975, mainly as antiarrhythmic and antihypertensive drugs. This group of compounds also possesses anti-inflammatory, ${ }^{3,4}$ anticonvulsant, anticoagulant, and antioxidant activities. ${ }^{5-7}$ Anticancer, antitubercular, and antiparasite activities have also been observed using in vitro systems. ${ }^{8-10}$ The $1,4-$ DHP core, when appropriately functionalized, interacts with diverse receptors and ion channels to exert a broad spectrum of pharmacological effects. ${ }^{11}$ This feature creates the potential to generate a class of molecules with novel physicochemical and biological properties. Structure-activity studies show that the nature and position of the substituents on 1,4-DHP's aryl ring determines their action. Clinical use is limited by the fact that 1,4-DHP derivatives also exhibit undesirable physicochemical properties 
such as low water solubility and photochemical sensitivity that can weaken their therapeutic effect. Studies of 1,4-DHP photo- and radiostability in solid phase have shown that these compounds are stable to $\beta$-radiation doses $<20 \mathrm{kGy}$. A higher dose of radiation decreases the melting point, causing decomposition of their structures and generation of free radicals. ${ }^{12}$ Some derivatives of 1,4-DHP also have significant toxicity against mammalian cells..$^{13,14}$

Studies of other pharmacological systems suggest that application of nanotechnology methods might improve the physicochemical and pharmacological properties of bioactive substances. Various nanomaterials including metal-oxide-based nanoparticles, liposomes, nanotubes, and dendrimers have been explored as drug delivery systems (DDS) to improve drug efficiency. The main purpose of nanoparticle-based delivery is to lower toxicity by improving drug uptake within the site of infection. Previous results show that the use of core-shell magnetic nanoparticles (MNPs) as a component of combined therapy or as drug carriers can enhance antimicrobial therapies and improve the treatment of bacterial and fungal infections, particularly those caused by antibiotic-resistant pathogens. ${ }^{15,16}$ Several metal oxides in the form of nanoparticles display marked antimicrobial properties due to their interaction with cell wall components, penetration into pathogen cells, controlled release of drugs, generation of reactive oxygen species (ROS), disruption of metabolic pathways, and destruction of intracellular organelles. ${ }^{17,18}$ As the number of infections caused by bacterial strains resistant to commonly used antibiotics increases, the clinical issues related to antibiotic resistance increases worldwide. ${ }^{19}$ One reason for this phenomenon is incorrect use of antibiotics in the treatment of bacterial and fungal infections. Overuse of carbapenems or glycopeptides plays a key role in the development of resistant bacteria and the resulting lack of effective treatment. ${ }^{20}$ Consequently, the search for new antimicrobial agents is a major challenge for modern medicine. In the present study, we evaluate the possibility to use magnetic nanosystems as DDS of novel 1,4-DHP derivatives against clinical isolates of pathogens. These studies show that covalent immobilization of 1,4DHP on aminosilane-coated MNPs markedly enhances their antimicrobial activity compared to nonimmobilized agents. Importantly, these novel nanosystems are characterized by better biocompatibility and higher anti-inflammatory activity. Application of nanotechnology (MNPs) in the connection with well-known drugs (in this case 1,4-DHP derivatives) produces new antimicrobial properties and enhances the opportunity to use these compounds in the treatment and diagnosis of various kinds of pathogens. Moreover, to the best of our knowledge, this is the first study where 1,4-DHP derivatives, known as privileged molecules and characterized by a pleiotropic mode of action, have been used in combination with magnetic nanocarriers. In effect, this combination provides the opportunity that the antimicrobial activity of these compounds might result in the fabrication of MNP-based compounds with a broad spectrum of biological activity.

\section{Methods}

\section{Synthesis of MNPs functionalized by I,4-DHP}

The magnetic core was synthesized using a well-known modification of the Massart method, which is based on the co-precipitation of hydrated iron chloride salts under treatment by ammonium hydroxide $(25 \%) .^{21}$ In the next step, Stöber methods were explored to obtain core-shell magnetic nanostructures with terminal propylo-amine groups. ${ }^{22}$ Immobilization of 1,4-DHP derivatives onto the surface of nanoparticles was achieved by reaction between the terminal aldehyde groups of nanoparticles and secondary amine groups from DHP. After functionalization, the precipitate was magnetically collected and washed with ethanol and phosphate-buffered saline (PBS) and then dried at $50^{\circ} \mathrm{C}$.

\section{Nanoparticle characterization}

Fourier-transform infrared (FT-IR) spectra were recorded under a Thermo Scientific Nicolet ${ }^{\mathrm{TM}}$ iNTM $^{\mathrm{T}} 10$ MX FT-IR microscope. A $10 \mu \mathrm{L}$ of sample $(1 \mathrm{mg} / \mathrm{mL})$ was dropped on the surface of a glossy metal plate, and the solvent was left to evaporate. All spectra were collected in the $4,000-800 \mathrm{~cm}^{-1}$ range by combining 64 scans with a resolution of $4 \mathrm{~cm}^{-1}$ and analyzed using the OMNIC software (Thermo Fisher Scientific, Waltham, MA, USA). Differential scanning calorimetry (DSC) was carried out using a Mettler Toledo Star DSC system. Nitrogen was used as a purge gas $(10 \mathrm{~mL} / \mathrm{min})$. Samples $(2 \mathrm{mg})$ were placed in aluminum pans and heated at $25^{\circ} \mathrm{C}-450^{\circ} \mathrm{C}$ with a heating rate of $20^{\circ} \mathrm{C} / \mathrm{min}$. Thermogravimetric analysis (TGA) was recorded using a Mettler Toledo Star TGA/DSC unit. Nanoparticles ( $2 \mathrm{mg})$ were placed in the aluminum pans $(40 \mu \mathrm{L})$ and heated at $50^{\circ} \mathrm{C}-900^{\circ} \mathrm{C}$ with a heating rate of $10^{\circ} \mathrm{C} / \mathrm{min}$.

\section{Determination of minimal inhibitory concentration (MIC)/minimal fungicidal concentration (MFC)/minimal biofilm inhibitory concentration (MBIC) values}

The bacterial and fungal strains used in this study were collected during the routine hospital laboratory procedure. The MIC, minimal bactericidal (MBC), and MFC were 
determined using pathogens at the logarithmic phase of growth. The activity of 1,4-DHP, MNP@1,4-DHP, and LL-37 at a concentration of $0.5-256 \mu \mathrm{g} / \mathrm{mL}$ was tested against the Gram-positive bacteria Staphylococcus aureus, methicillin-resistant S. aureus (MRSA), methicillinsusceptible $S$. aureus (MSSA), the Gram-negative bacteria Escherichia coli including extended spectrum $\beta$-lactamase (ESBL) strains and Pseudomonas aeruginosa (multidrug resistant [MDR]), and the fungus Candida sp. $\left(\sim 10^{3} \mathrm{CFU} / \mathrm{mL}\right)$. The MIC/MBC or MFC values were determined using the microdilution method. Metabolic activity was measured spectrophotometrically using a tetrazolium-based assay (3-(4,5-dimethylthiazol-2-yl)-2,5-diphenyltetrazolium bromide [MTT]) to evaluate the MBIC. ${ }^{23}$ The MIC values were determined visually (the lowest concentration of tested antimicrobial agents that inhibit pathogen growth). MBC and MFC were assessed by spotting the treated bacteria or fungi on Luria-Bertani (LB) agar or Sabouraud dextrose agar (SDA) plates, respectively.

\section{Zeta potential measurements}

Zeta potential measurements were performed using a Zetasizer Nano ZS (Malvern Instruments, Malvern, UK) at $25^{\circ} \mathrm{C}$ using $S$. aureus, E. coli, and $P$. aeruginosa bacterial strains incubated in the presence of uncoated MNPs and magnetic derivatives of 1,4-DHPs according to the protocol presented previously. ${ }^{24}$ For this purpose, overnight cultures of bacteria/fungi were brought to $\mathrm{OD}_{600} \sim 0.1$ in PBS ( $\left.\mathrm{pH}=7\right)$. Then, potential antibacterial agents were added at a concentration of $2.5 \mathrm{mg} / \mathrm{mL}$ and mixtures were transferred to a cuvette. Results are presented as a mean from three independent measurements.

\section{Outer membrane permeabilization assay}

$N$-phenyl-1-napthylamine (NPN) uptake was used to assess the outer membrane permeability of bacteria treated with 1,4-DHPs and MNP@1,4-DHPs. S. aureus, E. coli, and $P$. aeruginosa cells were suspended in PBS $\left(\mathrm{OD}_{600} \sim 0.1\right)$ prior to incubation with the 1,4-DHPs analogs (I-6, D-19, and $\mathrm{K}-180 \mathrm{~B}$ ) and their magnetic derivatives (MNP@I-6, MNP@D-19, and MNP@K-180B) in concentrations ranging from 1 to $100 \mu \mathrm{g} / \mathrm{mL}$. NPN was added to a final concentration of $0.5 \mathrm{mM}$, and the mixture was incubated for $5 \mathrm{~min}$. The increase in fluorescence intensity was recorded (excitation/ emission wavelengths 348/408 nm) using the Varioscan LUX Microplate Reader (Thermo Fisher Scientific).

\section{Chemiluminescence measurements}

Changes in the chemiluminescence intensity of $P$. aeruginosa Xen5 $\left(\mathrm{OD}_{600}=0.5\right)$ after treatment with tested agents with or without the presence of different body fluids (50\%) including plasma, fluid from the pleural cavity, serum, saliva, cerebrospinal fluid, abdominal fluid, and urine were determined as an additional method to assess bacterial viability.

\section{Kinetics of fungal cells' growth}

To assess how 1,4-DHPs and their MNP-based counterparts affect fungal growth, suspensions of Candida albicans, Candida glabrata, and Candida spp. clinical isolates were adjusted to $10^{5} \mathrm{CFU} / \mathrm{mL}$ in LB medium and incubated for $10 \mathrm{~min}$ with $100 \mu \mathrm{g} / \mathrm{mL}$ of the candidate antifungal agents. The rate of fungal growth was determined from the change in optical density for $10 \mathrm{~h}$ at $37^{\circ} \mathrm{C}$ using a Labsystems Varioscan $^{\mathrm{TM}}$ LUX (Thermo Fisher Scientific) apparatus.

\section{Cell culture of human keratinocytes}

Immortalized adult human skin keratinocytes (HaCaT) were grown in high-glucose Dulbecco's Modified Eagle's Medium supplemented with $10 \%$ fetal bovine serum, glutamine $(2 \mathrm{mM} / \mathrm{L})$, penicillin $(50 \mathrm{U} / \mathrm{mL})$, and streptomycin $(50 \mu \mathrm{g} / \mathrm{mL})$. The cells were maintained at $37^{\circ} \mathrm{C}$ in an atmosphere containing $5 \% \mathrm{CO}_{2}$ with saturated humidity.

\section{Assessment of nanosystems' biocompatibility}

Lactate dehydrogenase (LDH) release and MTT assays were performed to assess the safety of the nanosystems. For this purpose, HaCaT cells (American Type Culture Collection [ATCC], Manassas, VA, USA) were seeded in 96-well plates at a density of $5 \times 10^{4}$ cells/well in $200 \mu \mathrm{L}$ of growth medium and cultured until $80 \%$ confluence and serum starved for $24 \mathrm{~h}$. Then, cells were washed twice with PBS and treated with tested agents at concentrations ranging from 1 to $100 \mu \mathrm{g} / \mathrm{mL}$ over $24 \mathrm{~h}$. Results are presented as percentage of LDH release from treated cells when compared with untreated controls, with the amount of LDH in a suspension of lysed cells taken as $100 \% \mathrm{LDH}$ release. To confirm these results, the viability and metabolic activity of treated keratinocyte cells were measured with the MTT assay. The absorbance value obtained in cultures of control cells (without tested agents) was taken as $100 \%$. The average of all the experiments has been shown as cell viability percentage in comparison to the control.

\section{Assessment of IL-8 secretion induced with LPS}

In order to determine the IL-8 release from keratinocytes upon treatment with 1,4-DHP derivatives, $5 \times 10^{4}$ of $\mathrm{HaCaT}$ cells were seeded in 96-well plates and cultured until 80\% 
confluence was reached. Then, tested agents at concentrations 2,5 , and $10 \mu \mathrm{g} / \mathrm{mL}$ were added followed by stimulation with E. coli 026 :B6 LPS $(1 \mu \mathrm{g} / \mathrm{mL})$. The medium from stimulated cells was collected after $24 \mathrm{~h}$ of treatment, and the level of IL-8 was evaluated using an IL-8 Human enzyme-linked immunosorbent assay Kit (Thermo Fisher Scientific).

\section{ROS generation}

The generation of ROS in LPS-stimulated HaCaT cells was measured using $2^{\prime}, 7^{\prime}$-dichlorofluorescin diacetate (DFCH-DA). For this purpose, $5 \times 10^{4} \mathrm{HaCaT}$ cells were seeded in 96-well black plates with clear bottoms and cultured until 80\% confluence was reached. Cells were washed with $\mathrm{PBS}$, and tested agents at final concentrations 2, 5, and $10 \mu \mathrm{g} / \mathrm{mL}$ were added to corresponding well. Keratinocytes were stimulated with LPS $(1 \mu \mathrm{g} / \mathrm{mL}$ of $E$. coli 026:B6) and left for incubation in serum-free medium for $24 \mathrm{~h}$. Then, cells were washed twice with PBS and DFCH-DA in PBS at the final concentration of $20 \mu \mathrm{M}$ was added. Fluorescence was measured for $90 \mathrm{~min}$ immediately after dye addition using excitation/emission wavelengths $488 / 535 \mathrm{~nm}$. Cellular oxidant levels were expressed as relative DFCH-DA fluorescence value compared to untreated LPS-stimulated control samples.

\section{Statistical analysis}

Results were analyzed by one-tailed Student's $t$-test using Statistica 10 (StatSoft Inc, Tulsa, OK, USA). $P<0.05$ was considered as statistically significant. Results are the average from three to six measurements.

\section{Results}

\section{Synthesis and characterization of developed nanosystems}

Synthesis of aminosilane-modified magnetic nanocarriers was performed based on previously reported methods. Modification of Massart's coprecipitation was used to obtain the magnetic core. Subsequently, the polycondensation method was applied to create an aminosilane shell, which was then functionalized by glutaraldehyde. Immobilization of 1,4-DHPs was achieved by a nucleophilic addition reaction, where an enamine bond is formed between the aldehyde group and the amino group of 1,4-DHP (Figure 1A). To confirm the successful immobilization of 1,4-DHP on the aminosilane-coated MNPs, FT-IR spectra were recorded. Figure 1B-D shows the spectra of DHP derivatives before and after immobilization on MNPs. In all samples, the signals $\sim 3,400 \mathrm{~cm}^{-1}$ correspond to $\mathrm{N}-\mathrm{H}$ stretching vibrations.
The presence of methyl groups was confirmed by signals observed at $\sim 2,900$ and $\sim 2,800 \mathrm{~cm}^{-1}$, which correspond to symmetric and asymmetric $\mathrm{C}-\mathrm{H}$ stretching modes. Sequentially, the signals at $1,651,1,621$, and $1,648 \mathrm{~cm}^{-1}$ were ascribed to enamine bands that confirm successful immobilization of 1,4-DHP derivatives on the surface of the MNPs. Additionally, the signals $\sim 1,550 \mathrm{~cm}^{-1}$ correspond to $\mathrm{N}-\mathrm{H}$ deformation vibrations in-plane. In turn, before and after immobilization the signals recorded $\sim 1,450 \mathrm{~cm}^{-1}$ might be attributed to the asymmetrical deformation vibration $-\mathrm{CH}_{3}$. In comparison to the spectrum of the nonimmobilized agents, addition of MNPs leads to the appearance of a broad signal at $\sim 1,100 \mathrm{~cm}^{-1}$ (stretching vibration of $\mathrm{Si}-\mathrm{O}$ and $\mathrm{Si}-\mathrm{O}-\mathrm{Si}$ ) and also at $\sim 550 \mathrm{~cm}^{-1}$ ( $\mathrm{Fe}-\mathrm{O}$ stretching mode from the magnetic core) was observed. Moreover, the signals from the $\mathrm{N}-\mathrm{H}$ stretching vibration at $\sim 1,200 \mathrm{~cm}^{-1}, \mathrm{~N}-\mathrm{H}$ bending at $\sim 800 \mathrm{~cm}^{-1}$, and $\mathrm{C}-\mathrm{N}-\mathrm{C}$ signal deformation at $\sim 500 \mathrm{~cm}^{-1}$ are overlapped by broad signals from the aminosilane shell and the magnetic core. Comparable calorimetric analysis of 1,4-DHP derivatives in free solution and immobilized on MNPs is shown in Figure 1E. Similarity in the DSC curves between both forms of DHP derivatives was observed. In the case of the D-19 derivative, decreasing intensity of the endothermic peak $\sim 200^{\circ} \mathrm{C}$ and an offset of the maximum characteristic for exothermal transformation from $400^{\circ} \mathrm{C}$ to $350^{\circ} \mathrm{C}$ was observed. This tendency was also observed for derivatives of K-180B and I-6. Changes in the curves at temperatures between $300^{\circ} \mathrm{C}$ and $450^{\circ} \mathrm{C}$ are associated with decomposition of the aminosilane coating and with the exothermic degradation of the glutaraldehyde.

In order to determine the content of 1,4-DHP derivatives in the structure of nanosystems, TGA was used (Figure 1F and $\mathrm{G}$ ). According to previously published results, during decomposition of bare MNPs, the weight loss at the temperature range $50^{\circ} \mathrm{C}-800^{\circ} \mathrm{C}$ is $\sim 6 \%-8 \%$ and is directly connected with the removal of adsorbed water and the presence of hydroxyl groups on the surface. In turn, the weight loss associated with the degradation of the organosilane shell is $\sim 8 \%$. ${ }^{25}$ Based on these results as well as the course of decomposition curves, the content of the 1,4-DHP derivatives is $\sim 30 \%$. In the case of nanosystems, new peaks at $600^{\circ} \mathrm{C}$ and $800^{\circ} \mathrm{C}$ were observed and are ascribed to decomposition of the aminosilane coating of the magnetic core.

For additional confirmation of the presence of 1,4-DHP derivatives on the surface of nanoparticles, zeta potential analysis was performed (Figure $1 \mathrm{H}$ ). The surface charge of the aminosilane-coated MNPs was $+23 \mathrm{eV}$, whereas the electrokinetic potential of DHP-based nanosystems was 
A

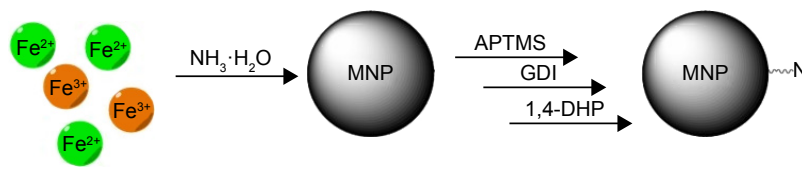

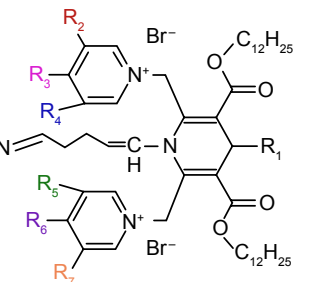

\begin{tabular}{|c|c|c|c|}
\hline $\begin{array}{l}\text { Functional } \\
\text { groups }\end{array}$ & D-19 & K-180B & I-6 \\
\hline $\mathrm{R}_{1}$ & - & - & - \\
\hline $\mathrm{R}_{2}$ & - & $\mathrm{CH}_{3}$ & - \\
\hline $\mathrm{R}_{3}$ & - & - & $\begin{array}{c}-\mathrm{N} \\
\text { I }\end{array}$ \\
\hline $\mathrm{R}_{4}$ & - & $\mathrm{CH}_{3}$ & - \\
\hline $\mathrm{R}_{5}$ & - & $\mathrm{CH}_{3}$ & - \\
\hline $\mathrm{R}_{6}$ & - & - & $\begin{array}{c}\mathrm{N}- \\
\text { I }\end{array}$ \\
\hline $\mathrm{R}_{7}$ & - & $\mathrm{CH}_{3}$ & - \\
\hline
\end{tabular}

C
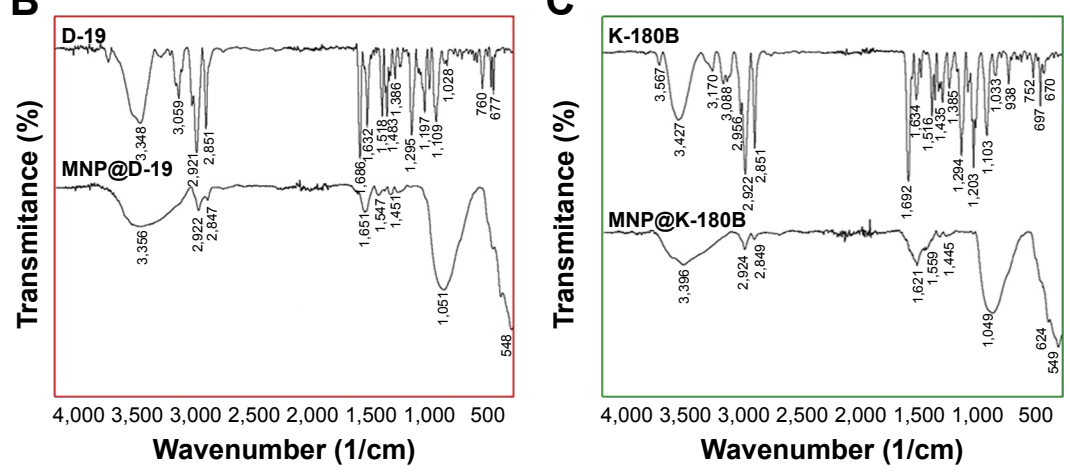

D

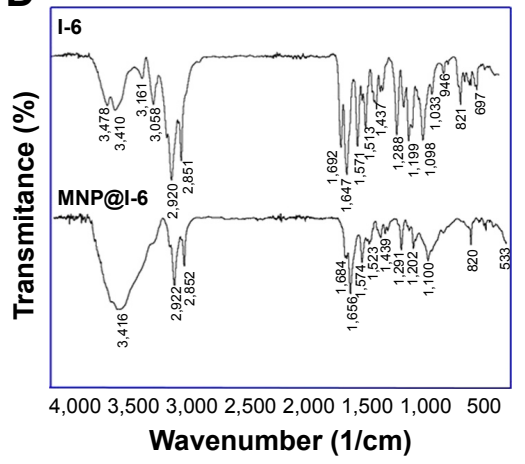

$\mathbf{F}$

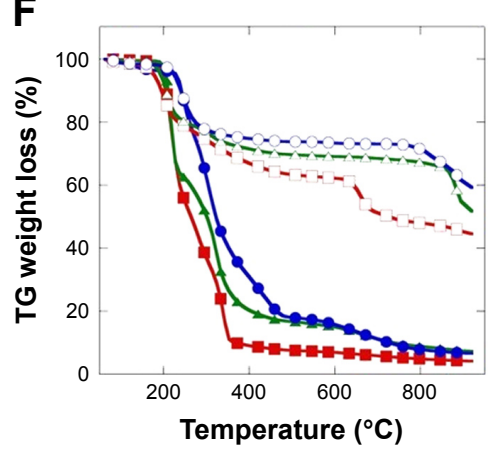

G

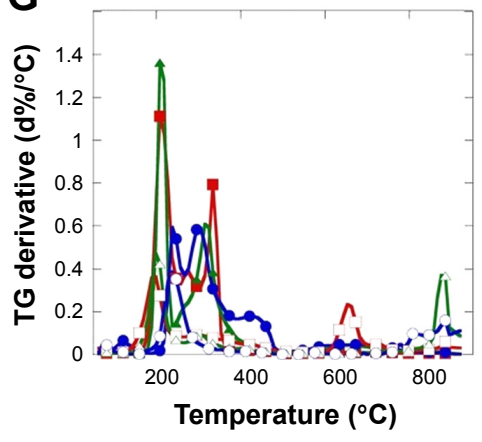

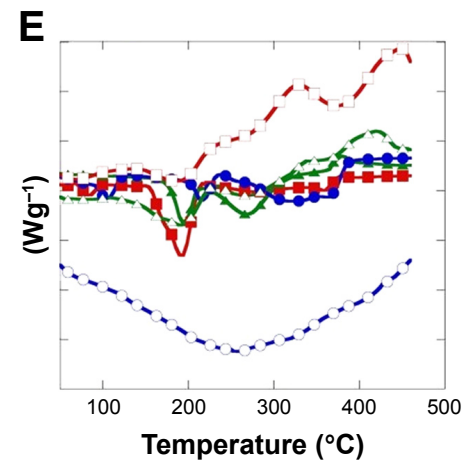

Temperature $\left({ }^{\circ} \mathrm{C}\right)$
H

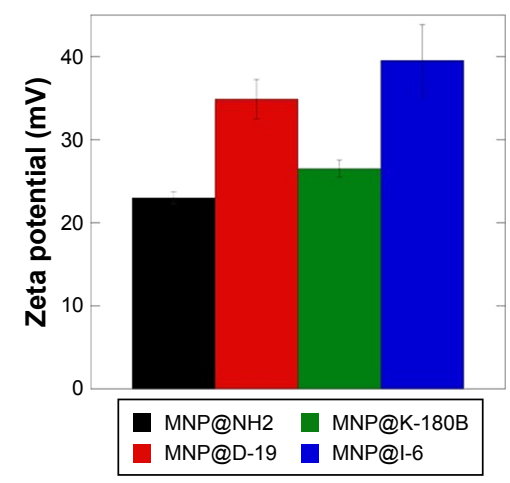

I

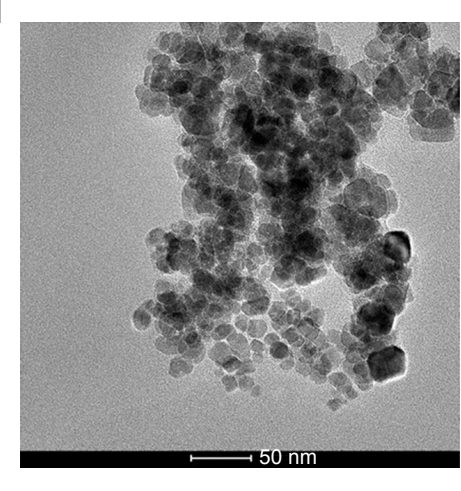

J

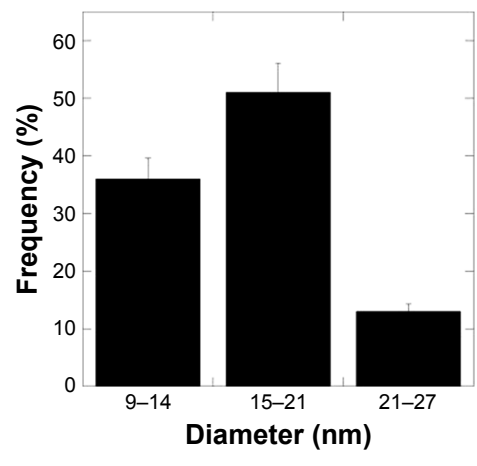

Figure I Physicochemical properties of I,4-DHP-functionalized MNPs.

Notes: Scheme of MNP synthesis and surface functionalization by I,4-DHP derivatives and chemical structure of the evaluated derivatives (A). Comparable ATR FT-IR spectra analysis of the I,4-DHP derivatives in free form and when attached to MNPs (B-D). DSC thermographs of free I,4-DHP derivatives and immobilized on MNPs' surface (E). Thermogravimetric analysis curves of I,4-DHP derivatives in free form and attached form (F and $\mathbf{G})$. Zeta potential of I,4-DHP-coated MNPs (H). TEM images and size distributions of MNP@I,4-DHP (I and $\mathbf{J})$.

Abbreviations: I,4-DHP, I,4-dihydropyridine; MNPs, magnetic nanoparticles; TEM, transmission electron microscopy; DSC, differential scanning calorimetry; ATR, attenuated total reflectance; FT-IR, Fourier transform infrared. 
determined to be $+30 \mathrm{mV}$. The high stability and positive character of these nanoparticles are important for their interaction with negatively charged pathogenic cells.

The size and shape of DHP-functionalized MNPs were evaluated by transmission electron microscopy. Nanoparticles possess spherical and regular shapes (Figure 1I), and $>50 \%$ of them range between 15 and $21 \mathrm{~nm}$ in diameter (Figure 1J). This result was additionally confirmed by X-ray diffraction analysis and is in agreement with our previously published studies..$^{15,26}$

\section{Antimicrobial activity of I,4-DHPs}

Antimicrobial activity was evaluated against representative strains of Gram-positive bacteria, Gram-negative bacteria and fungi. The analysis involved laboratory and clinical isolates of frequently occurring pathogenic strains including S. aureus, E. coli, P. aeruginosa, and Candida sp. (Table 1). Seven isolates of $S$. aureus, including the MRSA isolated

Table I Characteristic of pathogenic strains used

\begin{tabular}{|c|c|c|c|}
\hline No & Strains & Source & $\begin{array}{l}\text { Resistance } \\
\text { mechanism }\end{array}$ \\
\hline $\mathrm{I}$ & E. coli & Pus & Wild \\
\hline 2 & E. coli & Injury swab & ESBL $(+)$ \\
\hline 3 & E. coli & Urine & ESBL (+) \\
\hline 4 & E. coli & Rectal swab & ESBL $(+)$ \\
\hline 5 & E. coli & Blood & Wild \\
\hline 6 & E. coli & Rectal swab & ESBL $(+)$ \\
\hline 7 & E. coli & Blood & Wild \\
\hline 8 & E. coli & Laboratory strain & ND \\
\hline 9 & E. coli & Laboratory strain & ND \\
\hline 10 & E. coli & Laboratory strain & ND \\
\hline 11 & S. aureus & Injury swab & MSSA \\
\hline 12 & S. aureus & Blood & MSSA \\
\hline 13 & S. aureus & Blood & MSSA \\
\hline 14 & S. aureus & Throat swab & MRSA \\
\hline 15 & S. aureus & Laboratory strain & MRSA \\
\hline 16 & S. aureus & Laboratory strain & ND \\
\hline 17 & S. aureus & Laboratory strain & ND \\
\hline 18 & P. aeruginosa & CF sputum & Wild \\
\hline 19 & $P$. aeruginosa $L E S B$ & CF sputum & Wild \\
\hline 20 & P. aeruginosa & Laboratory strain & ND \\
\hline 21 & P. aeruginosa & Laboratory strain & ND \\
\hline 22 & Bacillus subtilis & Laboratory strain & ND \\
\hline 23 & C. albicans & Vaginal swab & FLU (R) \\
\hline 24 & C. albicans & Vaginal swab & Wild \\
\hline 25 & C. albicans & Throat swab & FLU (R) \\
\hline 26 & C. albicans & Laboratory strain & ND \\
\hline 27 & C. albicans & Laboratory strain & ND \\
\hline 28 & C. glabrata & Oral cavity swab & FLU (R) \\
\hline 29 & C. glabrata & Pus & FLU (R) \\
\hline 30 & C. tropicalis & Throat swab & Wild \\
\hline
\end{tabular}

Abbreviations: C. albicans, Candida albicans; CF, cystic fibrosis; C. glabrata, Candida glabrata; C. tropicalis, Candida tropicalis; E. coli, Escherichia coli; FLU (R), fluconazole resistant; MRSA, methicillin-resistant $S$. aureus; MSSA, methicillin-susceptible $S$. aureus; ND, not determined; P. aeruginosa, Pseudomonas aeruginosa; S. aureus, Staphylococcus aureus. from surface wounds, blood, and throat, were used to determine the killing activity against Gram-positive bacteria. The lowest MIC values (predominantly $64 \mu \mathrm{g} / \mathrm{mL}$ ) among 1,4-DHP derivatives in nonimmobilized form were observed for D-19 molecules and were comparable to values recorded for the cathelicidin peptide LL-37. In the case of nanosystems, the MIC/MBC and MBIC values were two - and even 16 - times lower than those observed for compounds in free form (Table 2). The antimicrobial activity of the 1,4-DHP derivatives against $E$. coli was assessed against 10 isolates, including ESBL strains collected from pus, urine, and blood. For most analyzed isolates, $\mathrm{MIC} / \mathrm{MBC} / \mathrm{MIBC}$ values of compounds in free form were $\sim 256 \mu \mathrm{g} / \mathrm{mL}$ (Table 3). However, in the case of nanosystems, two to four times higher activity was observed. In comparison to cationic antimicrobial peptides (CAPs) activity, the MIC/MBC and MBIC values are similar to those obtained for derivatives in nonimmobilized formula. The activity of test compounds against nonfermenting rods of $P$. aeruginosa was determined against four strains including two isolated from cystic fibrosis patients. The MIC/MBC values determined for derivatives of 1,4-DHP in free form were $\geq 256 \mu \mathrm{g} / \mathrm{mL}$ (Table 4 ). The lowest MIC was observed for I-6 $(64 \mu \mathrm{g} / \mathrm{mL})$. The above values were comparable to those obtained for cathelicidin LL-37. However, in the case of nanosystems, the activity was two to four times higher and was on average $128 \mu \mathrm{g} / \mathrm{mL}$. Evaluation of antifungal activity of the 1,4-DHP derivatives was performed by analyzing MIC/ MFC and MBIC values for eight Candida sp. strains. The microorganisms tested were from vagina, throat, oral cavity, and pus. Four of them showed resistance to fluconazole. The $\mathrm{MIC} / \mathrm{MFC}$ values for the analyzed derivatives of 1,4-DHP in nonimmobilized form were between 128 and $256 \mu \mathrm{g} / \mathrm{mL}$, suggesting that even up to 16 times higher concentrations $\left(\mathrm{MIC}_{\mathrm{D}-19}=128, \mathrm{MIC}_{\mathrm{MNP} @ \mathrm{D} 19}=8\right)$ are necessary to inhibit the growth of microorganisms compared to the DHP nanosystems (Table 5). The fungicidal activity (MIC/MFC) of CAPs' analogs representative for LL-37 was $\sim 64 / 128 \mu \mathrm{g} / \mathrm{mL}$. Additionally, evaluation of the ability to restrict the fungal growth by tested agents indicated that derivatives in immobilized form exert significantly better activity that compounds used in free form (Figure 2A-F). The analysis of growth curves of $C$. albicans showed that the 1,4-DHPs applied in the free form are able to inhibit fungal growth by $15 \%$ in the presence of K-180B, by $40 \%$ (I-6), and by $50 \%$ after the addition of D-19 (Figure 2A). In contrast, in the case of magnetic derivatives, total inhibition of the proliferation of the tested microorganisms was noted in comparison to the control values (Figure 2B). Similar observation was noted in the cases of other analyzed Candida species (Figure 2C-F). 
Table 2 Antimicrobial activity of dihydropyridine derivatives against selected clinical isolates of Staphylococcus aureus

\begin{tabular}{|c|c|c|c|c|c|c|c|}
\hline \multirow[t]{3}{*}{ Strains } & \multicolumn{7}{|l|}{ Drugs } \\
\hline & \multicolumn{7}{|c|}{ MIC/MBC/MBIC $(\mu \mathrm{g} / \mathrm{mL})$} \\
\hline & D-19 & K-I80B & $1-6$ & MNP@D-I9 & MNP@K-I80B & MNP@I-6 & LL-37 \\
\hline 11 & $64 / 128 / 128$ & $64 / 128 / 128$ & $128 / 256 / 256$ & $16 / 32 / 32$ & $64 / 64 / 64$ & $128 / 256 / 256$ & $32 / 64 / 64$ \\
\hline 12 & $256 / 256 />256$ & $128 / 256 / 256$ & $256 / 256 />256$ & $|28 /| 28 / \mid 28$ & $64 / 128 / 256$ & $64 / 128 / 256$ & $64 / 128 / 128$ \\
\hline 13 & $64 / / 28 / / 28$ & $128 / 256 / 256$ & $128 / 256 / 256$ & $32 / 64 / 64$ & $32 / 64 / 64$ & $|28 /| 128 / \mid 28$ & $16 / 32 / 64$ \\
\hline 14 & $128 / \mid 28 / 128$ & $128 / 256 / 256$ & $128 / 256 / 256$ & $32 / 32 / 64$ & $32 / 32 / 32$ & $|28 /| 128 / \mid 28$ & $|28 /| 28 / \mid 28$ \\
\hline 15 & $64 / 128 / 128$ & $128 / 128 / 256$ & $64 / 128 / 256$ & $32 / 64 / 64$ & $64 / 128 / 128$ & $64 / 128 / 256$ & $32 / 64 / 64$ \\
\hline 16 & $64 / 128 / 128$ & $128 / 128 / 128$ & $64 / 128 / 256$ & $32 / 64 / 64$ & $64 / 64 / 64$ & $64 / 128 / 128$ & $128 / 256 / 256$ \\
\hline 17 & $256 / 256 />256$ & I28/256/256 & $128 / 256 / 256$ & $16 / 16 / 32$ & $32 / 64 / 64$ & | 28/256/256 & $64 / 128 / 128$ \\
\hline
\end{tabular}

Abbreviations: MBC, minimal bactericidal; MBIC, minimal biofilm inhibitory concentration; MIC, minimal inhibitory concentration; MNP, magnetic nanoparticle.

\section{MNP@I,4-DHPs exert high affinity for bacterial membranes}

As presented in Figure $3 \mathrm{~A}-\mathrm{C}$, all nanosystems change the overall surface charge of bacteria from strongly negative $(\sim-20 \mathrm{mV}$ ) to positive values of $\sim+30 \mathrm{mV}$ (MNP@D-19). Importantly, this effect is not strain dependent, which indicates that membrane affinity of these compounds is conditioned by molecular charge, and not by the chemical composition of the bacterial membrane. The high affinity of the nanosystems for cell membranes was confirmed by the NPN assay. According to the results presented in Figure 3D-F, immobilization of developed derivatives of 1,4-DHPs on MNPs significantly increases their membrane affinity.

\section{The antibacterial activity of MNP@I,4- DHPs is maintained when suspended in different human body fluids}

The presence of factors inhibiting the killing activity of antimicrobial agents, such as proteases, ions, mucin in saliva, and apolipoprotein A in serum, considerably limits the clinical potential of some newly synthetized antibiotics. ${ }^{27}$ Considering these reports, it is crucial to develop structures with a broad spectrum of antimicrobial activity that is maintained in chemically complex settings, such as body fluids. According to the results in Figure 4, all 1,4-DHP analogs presented in this study inhibit the metabolic activity of $P$. aeruginosa Xen5, despite the presence of body fluids. The inhibitory effect of these agents is comparable with the activity detected in LB medium. This result suggests that the presence of factors functioning as antibiotic inhibitors (eg, negatively charged biopolymers) in various body fluids does not affect their killing activity.

\section{The attachment of I,4-DHPs to MNPs improves their biocompatibility}

Previous studies demonstrated that immobilization of antimicrobial agents on the surface of magnetic nanocarriers significantly improves their bactericidal activity and diminishes their toxic effects against host cells. ${ }^{28}$ To investigate how immobilization of 1,4-DHPs derivatives on the surface of MNPs affects their toxicity toward normal human cells, we performed analyses in which the integrity and metabolic activity of $\mathrm{HaCaT}$ cell were assessed. Data in Figure 5A and B show that DHP-based nanosystems are

Table 3 Antimicrobial activity of dihydropyridine derivatives against selected clinical isolates of Escherichia coli

\begin{tabular}{|c|c|c|c|c|c|c|c|}
\hline \multirow[t]{3}{*}{ Strains } & \multicolumn{7}{|l|}{ Drugs } \\
\hline & \multicolumn{7}{|c|}{ MIC/MBC/MBIC $(\mu \mathrm{g} / \mathrm{mL})$} \\
\hline & D- 19 & K-I80B & 1-6 & MNP@D-I9 & MNP@K-I80B & MNP@I-6 & LL-37 \\
\hline I & $\mid 28 / 256 />256$ & $>256 />256 />256$ & $>256 />256 />256$ & $64 / 128 / 128$ & $128 / 256 / 256$ & $128 / 256 / 256$ & $64 / 128 / 128$ \\
\hline 2 & $>256 />256 />256$ & $>256 />256 />256$ & $>256 />256 />256$ & $>256 />256 />256$ & $>256 />256 />256$ & $>256 />256 />256$ & $256 />256 />256$ \\
\hline 3 & $>256 />256 />256$ & $>256 />256 />256$ & $>256 />256 />256$ & $>256 />256 />256$ & $>256 />256 />256$ & $>256 />256 />256$ & $256 />256 />256$ \\
\hline 4 & $>256 />256 />256$ & $>256 />256 />256$ & $>256 />256 />256$ & $128 / 128 / 256$ & $128 / 128 / 128$ & $256 / 256 / 256$ & $256 />256 />256$ \\
\hline 5 & $>256 />256 />256$ & $>256 />256 />256$ & $>256 />256 />256$ & $64 / 128 / 128$ & $128 / 256 / 256$ & $256 / 256 / 256$ & $64 / 64 / 128$ \\
\hline 6 & $>256 />256 />256$ & $>256 />256 />256$ & $>256 />256 />256$ & $>256 />256 />256$ & $128 / 128 / 256$ & $128 / 128 / 128$ & $128 / 128 / 128$ \\
\hline 7 & $256 / 256 />256$ & $>256 />256 />256$ & $>256 />256 />256$ & $|28 /| 28 />256$ & $128 / 128 / 256$ & $|28 /| 28 />256$ & $256 / 256 />256$ \\
\hline 8 & $128 / 128 / 128$ & $64 / 128 / 128$ & $256 / 256 />256$ & $64 / 128 / 128$ & $64 / 64 / 128$ & $128 / 256 / 256$ & $128 / 128 / 128$ \\
\hline 9 & $64 / 64 / 64$ & $128 / 128 / 256$ & $128 / 256 / 256$ & $32 / 64 / 64$ & $16 / 32 / 32$ & $64 / 64 / 64$ & $64 / 128 / 128$ \\
\hline 10 & $64 / 128 / 128$ & $64 / 128 / 128$ & $64 / 64 / 128$ & $16 / 16 / 32$ & $16 / 16 / 32$ & $16 / 16 / 64$ & $32 / 32 / 64$ \\
\hline
\end{tabular}

Abbreviations: MBC, minimal bactericidal; MBIC, minimal biofilm inhibitory concentration; MIC, minimal inhibitory concentration; MNP, magnetic nanoparticle. 
Table 4 Antimicrobial activity of dihydropyridine derivatives against selected clinical isolates of Pseudomonas aeruginosa

\begin{tabular}{|c|c|c|c|c|c|c|c|}
\hline \multirow[t]{3}{*}{ Strains } & \multicolumn{7}{|l|}{ Drugs } \\
\hline & \multicolumn{7}{|c|}{ MIC/MBC/MBIC ( $\mu \mathrm{g} / \mathrm{mL})$} \\
\hline & D-19 & K-I 80B & I-6 & MNP@D-I9 & MNP@K-I80B & MNP@I-6 & LL-37 \\
\hline 18 & $128 / 256 / 256$ & $128 / 256 / 256$ & $64 / 128 / 256$ & $128 / 256 / 256$ & $128 / 256 / 256$ & $64 / 64 / 128$ & $64 / 128 />256$ \\
\hline 19 & $256 />256 />256$ & $256 / 256 />256$ & $128 / 128 / 256$ & $128 / 256 / 256$ & $|28 /| 128 / 256$ & $64 / 64 / 128$ & $>256 />256 />256$ \\
\hline 20 & $>256 />256 />256$ & $>256 />256 />256$ & $>256 />256 />256$ & $128 / 256 / 256$ & $256 / 256 / 256$ & $256 / 256 / 256$ & $|28 /| 28 />256$ \\
\hline 21 & $256 / 2>256 />256$ & $>256 />256 />256$ & $>256 />256 />256$ & $64 / 128 / 128$ & $64 / 128 / 256$ & $>256 />256 />256$ & $>256 />256 />256$ \\
\hline
\end{tabular}

Abbreviations: MBC, minimal bactericidal; MBIC, minimal biofilm inhibitory concentration; MIC, minimal inhibitory concentration; MNP, magnetic nanoparticle.

characterized by lower toxicity to keratinocyte cells when compared with their nonmodified counterparts, particularly at lower doses ranging from 1 to $20 \mu \mathrm{g} / \mathrm{mL}$. The lowest cytotoxicity in a broad spectrum of concentration was detected for I-6 and MNP@I-6 considering that the number of HaCaT cells losing cell membrane impermeability did not exceed $\sim 30 \%$ up to doses $100 \mu \mathrm{g} / \mathrm{mL}$.

\section{I,4-DHPs both in free form and attached to magnetic nanocarriers exert anti- inflammatory properties}

IL-8 is one of the major cytokines produced by keratinocytes, monocytes, and macrophages that is overexpressed upon stimulation with proinflammatory factors such as LPS. ${ }^{29}$ As shown in Figure 5C, DHPs decreased the LPS-induced secretion of IL-8 from HaCaT cells in a dose-dependently manner. The enzyme-linked immunosorbent assay measurements demonstrated that the concentration of IL-8 in the supernatants of LPS-stimulated cells decreased from $139.4 \pm 0.2$ to $122 \pm 1,78 \pm 8$, and $68 \pm 8 \mathrm{pg} / \mathrm{mL}$ in samples incubated in $10 \mu \mathrm{g} / \mathrm{mL} \mathrm{I}-6$, D-19, and K-180B, respectively. Further decline of IL-8 secretion by $\sim 25 \%$ was detected when LPS activation was performed in the presence of MNP@I-6 and MNP@K-180B. These data indicate that nanosystems have stronger anti-inflammatory properties than their nonmodified counterparts. This difference depends on the molecular properties of the nanostructure as indicated by the low effect of D-19-based nanosystems.

\section{Both I,4-DHPs and DHP-based nanosystems protect cells from oxidative stress}

ROS can amplify a variety of proinflammatory pathways, including those mediated by NF- $\kappa \mathrm{B}$ and JNK. An increase in their formation is observed upon IL- $1 \beta$, TNF- $\alpha$, or LPS stimulation. ${ }^{30}$ We examined ROS generation upon LPS treatment and found that exposure of cells to $1 \mu \mathrm{g} / \mathrm{mL}$ LPS for $24 \mathrm{~h}$ caused an $>12$-fold increase in ROS levels, when compared with unstimulated control. A significant decrease in this value was observed for cells treated with 1,4-DHP derivatives, particularly at doses 5 and $10 \mu \mathrm{g} / \mathrm{mL}$ (Figure 5D), which indicates that these agents protect the cells from lipopolysaccharide-induced oxidative stress. K-180B exerts the strongest ability to prevent ROS formation. Its magnetic counterpart, $\mathrm{MNP} @ \mathrm{~K}-180 \mathrm{~B}$, at doses range 5-10 $\mu \mathrm{g} / \mathrm{mL}$ resulted in 2- to 4-fold decrease in ROS formation. Immobilization on MNPs also improves the protective properties of I-6.

Table 5 Antimicrobial activity of dihydropyridine derivatives against selected clinical isolates of Candida sp.

\begin{tabular}{|c|c|c|c|c|c|c|c|}
\hline \multirow[t]{3}{*}{ Strain } & \multicolumn{7}{|l|}{ Drugs } \\
\hline & \multicolumn{7}{|c|}{ MIC/MBC/MBIC $(\mu \mathrm{g} / \mathrm{mL})$} \\
\hline & D-19 & $K-180 B$ & I-6 & MNP@D-I9 & MNP@K-I80B & MNP@I-6 & LL-37 \\
\hline 23 & $|28 / 256|>256$ & $128 / 256 / 256$ & $128 / 128 / 256$ & $8 / 16 / 16$ & $32 / 64 / 64$ & $|28 /| 28 / \mid 28$ & $64 / 128 / 256$ \\
\hline 24 & $|28 / 256|>256$ & $256 / 256 />256$ & $256 / 256 />256$ & $128 / 256 / 256$ & $64 / 128 / / 28$ & $|28 /| 28 / 256$ & $|28 /| 28 />256$ \\
\hline 25 & $|28 / 256|>256$ & $256 / 256 />256$ & $128 / 256 / 256$ & $64 / 128 / 128$ & $64 / 128 / 128$ & $128 / 128 / 128$ & $|28 /| 28 />256$ \\
\hline 26 & $\mid 28 / 256 />256$ & $\mid 28 / 256 />256$ & $128 / 256 / 256$ & $16 / 32 / 64$ & $64 / 128 / 128$ & $64 / 128 / 128$ & $64 / 64 / 128$ \\
\hline 27 & $|28 / 256|>256$ & $|28 / 256|>256$ & $64 / 64 / 128$ & $32 / 64 / 128$ & $64 / 128 / 256$ & $64 / 128 / 256$ & $|28 /| 28 />256$ \\
\hline 28 & $|28 / 256|>256$ & $|28 / 256|>256$ & $|28 / 256|>256$ & $32 / 64 / 64$ & $|28 /| 28 / 256$ & $32 / 64 / 128$ & $64 / 128 / 256$ \\
\hline 29 & $256 / 256 />256$ & $128 / 256 / 256$ & $256 / 256 />256$ & $64 / 128 / 128$ & $|28 /| 28 / 256$ & $128 / 128 / 128$ & $64 / 128 / 256$ \\
\hline 30 & $256 / 256 />256$ & $256 />256 />256$ & $256 / 256 />256$ & $128 / 256 / 256$ & $64 / 64 / 128$ & $64 / 64 / 128$ & $64 / 64 />256$ \\
\hline
\end{tabular}

Abbreviations: $\mathrm{ESBL}$, extended spectrum $\beta$-lactamase; MBC, minimal bactericidal; MBIC, minimal biofilm inhibitory concentration; MIC, minimal inhibitory concentration; MNP, magnetic nanoparticle. 

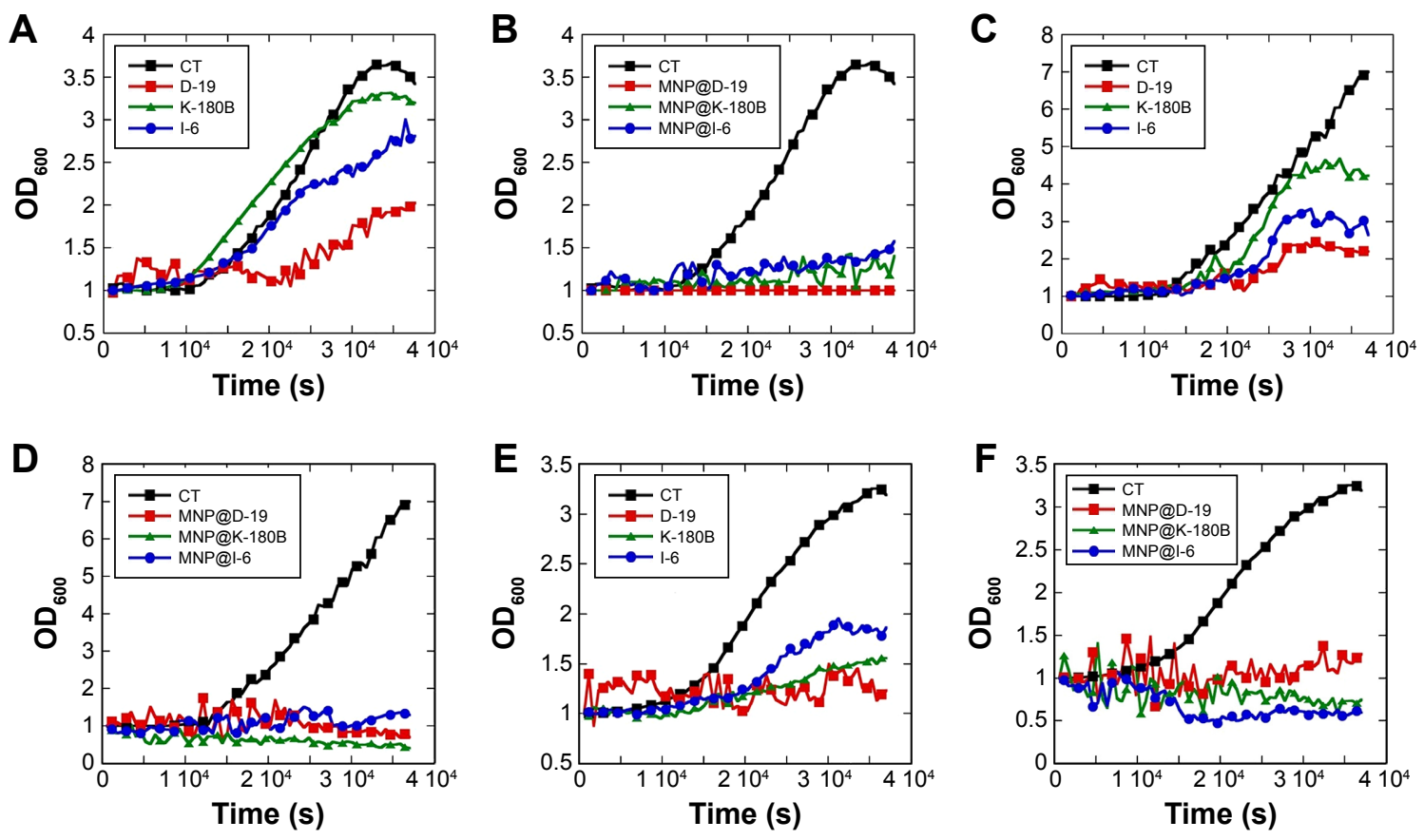

Figure 2 MNPs enhance the I,4-DHP ability to inhibit the fungal growth.

Note: Kinetic growth curves of Candida albicans (A and B), Candida glabrata (C and D) and Candida spp. (E and F) after treatment by I,4-DHP derivatives in free form and immobilized on MNPs.

Abbreviations: I,4-DHP, I,4-dihydropyridine; CT, control; MNPs, magnetic nanoparticles.
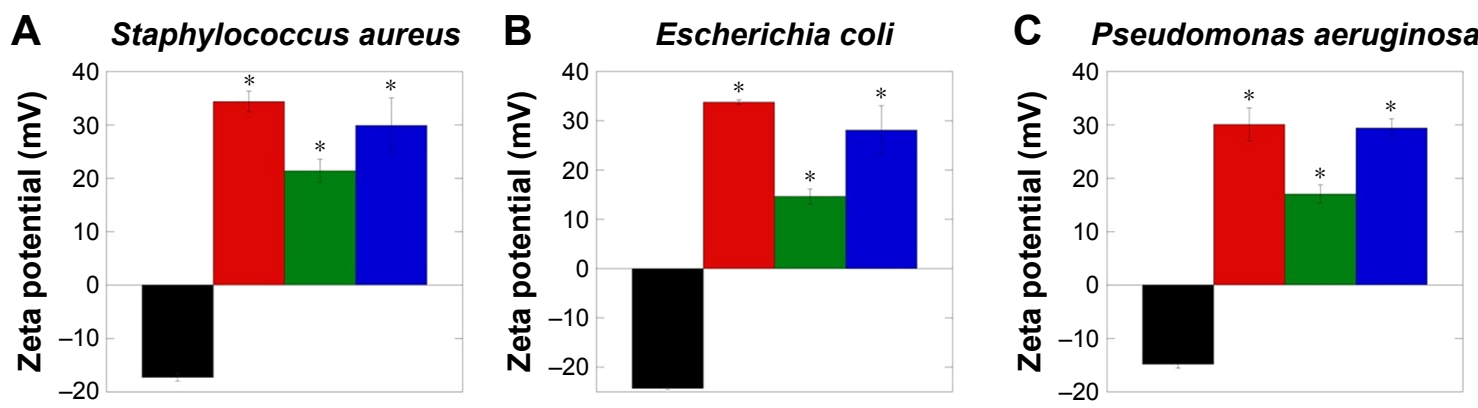

Control $\quad$ MNP@D-19

D

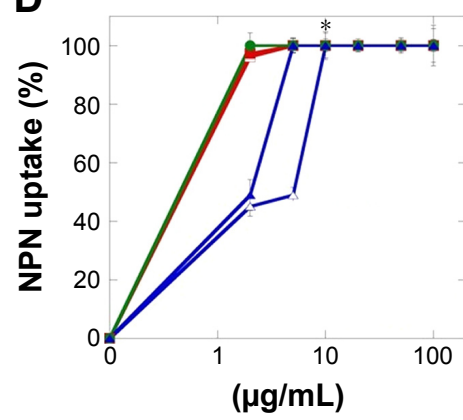

E

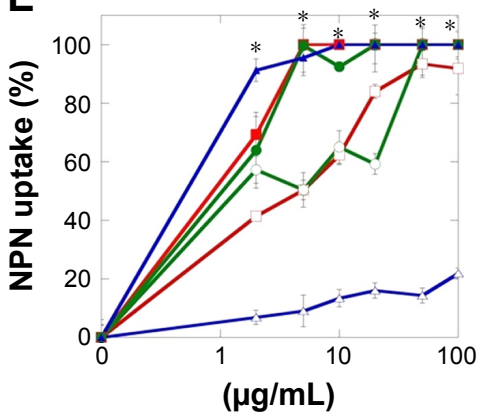

$\mathbf{F}$

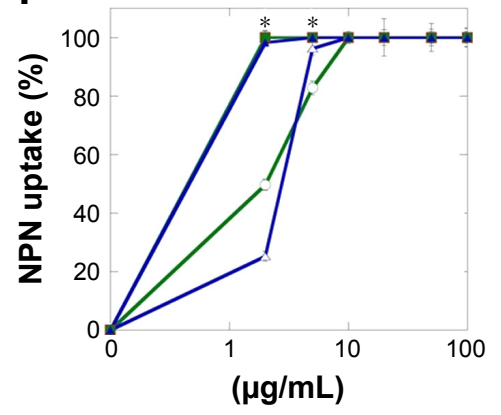

$\longrightarrow$ D-19 $\longrightarrow$ K-180B $-\mathrm{I}-6 \rightarrow$ MNP@D-19 $\multimap$ MNP@K-180B $\multimap$ MNP@I-6

Figure 3 Interaction of I,4-DHP-decorated MNPs with bacterial membrane.

Notes: Changes in bacterial surface charge after the addition of I,4-DHP-decorated MNPs (A-C). NPN uptake into outer membrane of representatives of Gram-positive and Gram-negative bacteria cells after treatment by I,4-DHP derivatives in free form and immobilized on MNPs (D-F). Results represent mean \pm SD obtained from three experiments. *Statistically significant $(P \leq 0.05)$ activity of MNPs decorated by I,4-DHP compared to nonimmobilized agents.

Abbreviations: I,4-DHP, I,4-dihydropyridine; MNPs, magnetic nanoparticles; NPN, N-Phenyl-I-naphthylamine. 


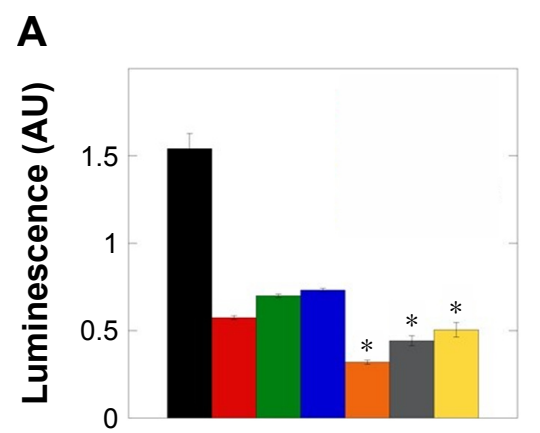

D

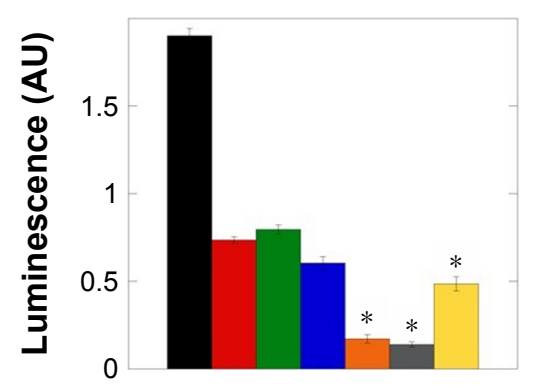

B

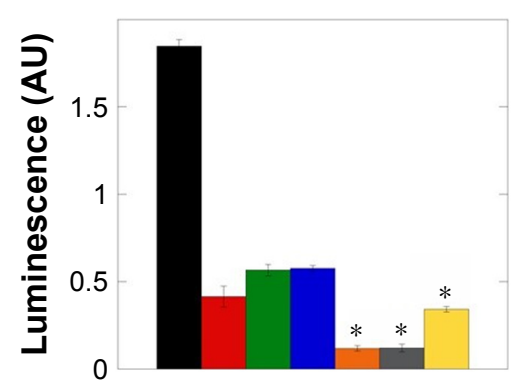

E

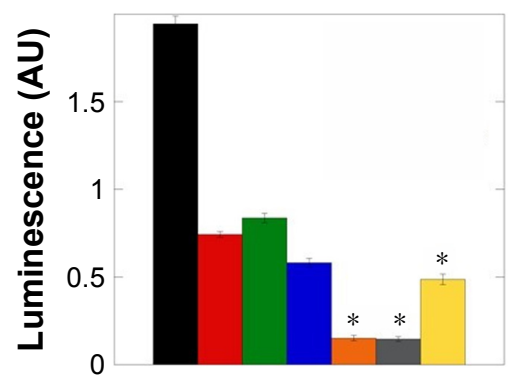

C

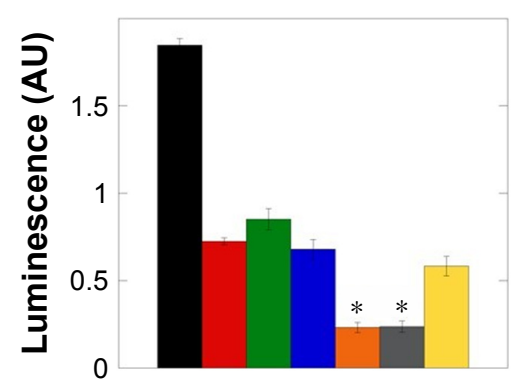

$F$

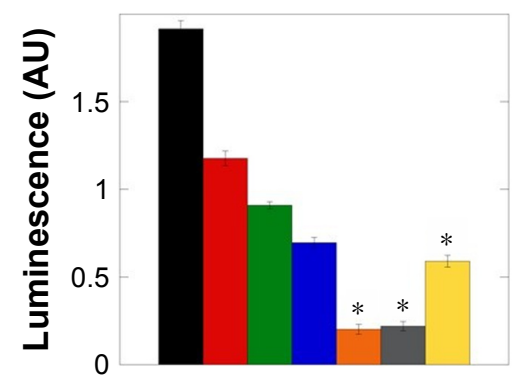

G

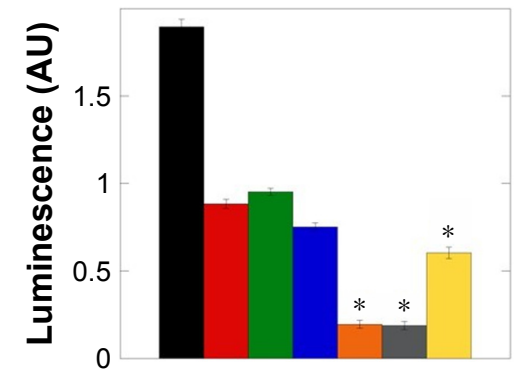

H

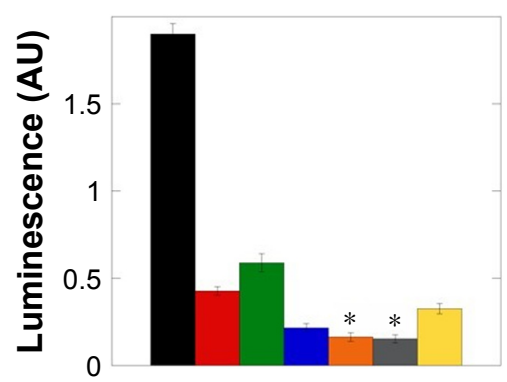

$\square \mathrm{CT} \square \mathrm{D}-19 \square \mathrm{K}-180 \mathrm{~B} \square \mathrm{I}-6 \quad \square \mathrm{MNP} @ \mathrm{D}-19 \square \mathrm{MNP} @ \mathrm{~K}-180 \mathrm{~B} \square \mathrm{MNP} @ \mathrm{I}-6$

Figure 4 MNPs enhance antibacterial properties of I,4-DHP derivatives in the presence of human body fluids.

Notes: The ability of I,4-DHP in free and immobilized on MNPs surface forms to restrict metabolic activity and viability of Pseudomonas aeruginosa Xen5 in the presence of LB broth and some body fluids: (A) LB broth media; (B) plasma; (C) serum; (D) saliva; (E) cerebrospinal fluid; (F) abdominal fluid; (G) fluid from the pleural cavity; and $(\mathbf{H})$ urine. Results represent mean \pm SD obtained from three experiments. *Statistically significant $(P \leq 0.05)$ activity of MNPs decorated by I,4-DHP compared to nonimmobilized agents.

Abbreviations: I,4-DHP, I,4-dihydropyridine; CT, control; LB, Luria-Bertani; MNPs, magnetic nanoparticles.

\section{Discussion}

Despite a large number of antibiotics and chemotherapeutics available for medical purposes, the successive treatment of bacterial and fungal infections remains a significant scientific challenge, particularly due to ever-growing development of antibiotic-resistant pathogens. To date, a majority of diseaseassociated microbes, including Klebsiella pneumoniae, P. aeruginosa, Acinetobacter baumannii, Clostridium difficile, E. coli, and $S$. aureus, have developed resistance to antimicrobial agents, which considerably hampers the effective eradication of these pathogens and is followed by increased microbial-linked morbidity and mortality and higher economical costs of antibiotic therapy. ${ }^{31}$ Antibiotic resistance is an interdisciplinary problem, combining different fields of science, such as chemical synthesis, cell biology, microbiology, and pharmacology. Therefore, the search for novel structures with wide spectra of antibacterial and antifungal activities is needed. Compounds from the group of 1,4-dihydropyridynes have potential for novel therapeutic applications. To date, they are used mainly 

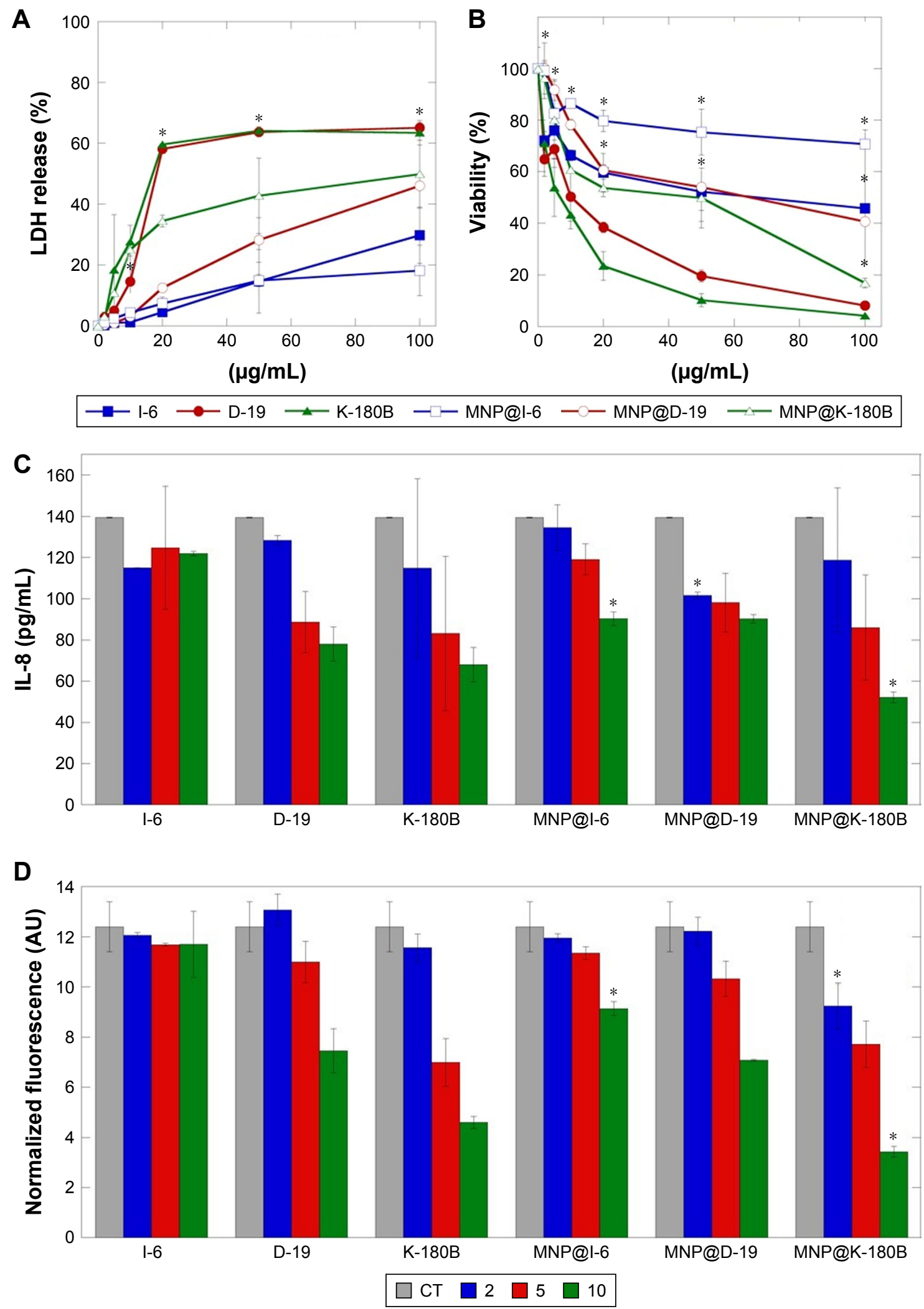

Figure 5 Biocompatibility and immunomodulatory properties of I,4-DHP-functionalized MNPs.

Notes: Release of LDH and viability of $\mathrm{HaCaT}$ cells after treatment by I,4-DHP derivatives in free form and immobilized on MNPs (A and B). IL-8 release and the generation of ROS from LPS-stimulated HaCaT cells after treatment by I,4-DHP derivatives in free form and immobilized on MNPs (C and D). Results represent mean \pm SD obtained from three experiments. *Statistically significant $(P \leq 0.05)$ activity of MNPs decorated by I,4-DHP compared to nonimmobilized agents.

Abbreviations: I,4-DHP, I,4-dihydropyridine; CT, control; LDH, lactate dehydrogenase; MNPs, magnetic nanoparticles; ROS, reactive oxygen species. 
for the treatment of cardiovascular diseases, including hypertension, ${ }^{32}$ but recent studies revealed that 1,4-DHPs apart from their well-known activity as $\mathrm{Ca}^{2+}$ channel blockers, might also be developed as novel agents with antioxidant, ${ }^{33}$ anticancer, ${ }^{10}$ antidiabetic,${ }^{34}$ antiparasite, ${ }^{35}$ and antimicrobial ${ }^{36}$ properties. The activity of $1,4-$ DHPs is determined by their chemical nature, and it has been established that the type of C-3, C-4, and C-5 substituent and the lipophilicity of these agents have important effects on antimicrobial activity. Their amphipathic nature should promote insertion into the microbial membrane, which suggests that 1,4-DHPs might function similarly to CAPs. Such a mode of action that is based on nonspecific interaction of antibacterial agent with plasma membrane (change in membrane phospholipid organization and membrane permeabilization) is characterized by a broad antibacterial spectrum and is difficult to evade by bacteria using antibiotic resistance mechanisms. Indeed, the antibacterial activity of 1,4-DHPs derivatives was already observed against Bacillus subtilis, S. aureus, E. coli, Proteus vulgaris, and Mycobacterium tuberculosis. ${ }^{10,36}$ Importantly, it was also shown that DHP derivatives exert antifungal activity against C. albicans and Aspergillus fumigatus, but with much lower hemotoxicity when compared with amphotericin B. ${ }^{37}$ Moreover, their antimicrobial activity and ability to reverse MDR drug resistance has drawn attention of many researchers. ${ }^{38,39}$ In this way, a large number of new derivatives of DHPs were synthesized and some of them have reached the upper stage of preclinical studies. One way to improve or modulate their biological properties including antimicrobial, pharmacological, and bioavailability effects is the use of nanocarriers. Among several kinds of nanoscaled transporters, the most interesting seem to be magnetic derivatives, which are approved by the US FDA as MRI contrast agents and are in clinical trials. ${ }^{40}$ Iron oxide-based nanoparticles have already been extensively studied for their promising use in biomedical technology including therapeutic and diagnostic areas. $^{41,42}$ In agreement with these reports, we examined new 1,4-DHPs derivatives that possess antimicrobial activity against both Gram-positive and Gram-negative bacteria and clinical isolates of Candida strains. Importantly, their activity might be enhanced by immobilization on the surface of iron oxide-based MNPs. To date, MNPs by themselves have been proposed as active agents against bacterial and fungal pathogens that function by the penetration of MNPs through the microbial membrane, contribution to ROS generation, interference with bacterial electron transport of oxidation of $\mathrm{NADH}$, damage of macromolecules including DNA, lipids, and proteins, and disruption of multilayered structure of microbial biofilms. ${ }^{43,44}$ Indeed, functionalization of MNPs using 1,4-DHPs with antimicrobial properties modulates their biological activity and expands their antimicrobial spectrum. Synthesis of such nanosystems also provides a way to develop novel synergistic therapeutic strategies that might be applicable for the treatment of infections caused by drug-resistant strains. Previously, Akbarzadeh et $\mathrm{al}^{45}$ demonstrated that combination of 1,4-DHPs derivatives with cloxacillin might be effective against cloxacillin-resistant strains of MRSA. As presented here, antimicrobial activity of 1,4-DHP derivatives was determined by the high affinity of these compounds to the bacterial membrane and potential possibility to penetrate biopolymer network. ${ }^{46,47}$ Moreover, the synergistic effects of nanoparticles and antibiotics have been extensively reported in the literature. ${ }^{48}$ Our previous report showed that the combination of antibacterial agents with MNPs increases their bactericidal effect. ${ }^{15}$ Importantly, enhancement of antimicrobial properties of antibiotic and other active agents, achieved using nanostructures, was observed in case of covalent and electrostatic-based immobilization. ${ }^{16}$ In the era of constantly increasing bacterial and fungal resistance to conventional antimicrobial therapy especially in the case of multidrug-resistant strains, combined therapy has been shown as one way to delay and overcome bacterial resistance. This treatment strategy allows the use of lower doses of drugs compared to monodrug therapy, which improves the chances that side effects will be restricted. These results suggest the possibility of combining 1,4-DHP derivatives with MNPs to treat pathogenic infections in typical or synergistic manner.

\section{Conclusion}

This study shows that aminosilane-coated iron oxide MNPs are an important material for the creation of nanosystems that provide the opportunity for selective drug transport and its controlled release at the target site. Immobilization of 1,4-DHP on a magnetic carrier produces greater antibacterial and antifungal activities in relation to the tested pathogens strains, in comparison with 1,4-DHP derivatives in free form. Importantly, these nanosystems possess greater antimicrobial activity than human cathelicidin LL-37 and similar to the activity of the cationic lipid CSA-13. They also inhibit the proinflammatory properties of bacterial cell wall components, which is a significant advance in creation of a novel class of multimodal agents for the treatment of life-threatening infections.

\section{Acknowledgments}

This study was supported by the National Science Center, Poland, under grant UMO-2015/17/B/NZ6/03473 (to RB). 
In 2016, KN-L was awarded a fellowship from the Foundation for Polish Science (FNP). This study was conducted with the use of equipment purchased by the Medical University of Białystok as a part of the RPOWP 2007-2013 funding, Priority I, Axis 1.1, contract no UDA-RPPD.01.01.00-20001/15-00 dated June 26, 2015.

\section{Disclosure}

The authors report no conflicts of interest in this work.

\section{References}

1. Yang J, Jiang C, Yang J, Qian C, Fang D. A clean procedure for the synthesis of 1,4-dihydropyridines via Hantzsch reaction in water. Green Chem Lett Rev. 2013;6(3):262-267.

2. Filipan-Litvić M, Litvić M, Cepanec I, Vinković V. Hantzsch synthesis of 2,6-dimethyl-3,5-dimethoxycarbonyl-4-(o-methoxyphenyl)-1,4dihydropyridine; a novel cyclisation leading to an unusual formation of 1-amino-2-methoxy-carbonyl-3,5-bis(o-methoxyphenyl)-4-oxacyclohexan-1-ene. Molecules. 2007;12(11):2546-2558.

3. Khedkar SA, Auti PB. 1,4-Dihydropyridines: a class of pharmacologically important molecules. Mini Rev Med Chem. 2014;14(3):282-290.

4. Yamagishi S, Nakamura K, Takenaka K, Matsui T, Inoue H. Pleiotropic effects of nifedipine on atherosclerosis. Curr Pharm Des. 2006;12(12): 1543-1547.

5. Toma L, Stancu CS, Sanda GM, Sima AV. Anti-oxidant and antiinflammatory mechanisms of amlodipine action to improve endothelial cell dysfunction induced by irreversibly glycated LDL. Biochem Biophys Res Commun. 2011;411(1):202-207.

6. Prasanthi G, Prasad KV, Bharathi K. Synthesis, anticonvulsant activity and molecular properties prediction of dialkyl 1-(di(ethoxycarbonyl) methyl)-2,6-dimethyl-4-substituted-1,4-dihydropyridine-3,5dicarboxylates. Eur J Med Chem. 2014;73:97-104.

7. Kumar RS, Idhayadhulla A, Abdul Nasser AJ, Selvin J. Synthesis and anticoagulant activity of a new series of 1,4-dihydropyridine derivatives. Eur J Med Chem. 2011;46(2):804-810.

8. Kumar R, Idhayadhulla A, Abdul Nasser A, Selvin J. Synthesis and antimicrobial activity of a new series of 1,4-dihydropyridine derivatives. J Serb Chem Soc. 2011;76(1):1-11.

9. Reimão JQ, Scotti MT, Tempone AG. Anti-leishmanial and antitrypanosomal activities of 1,4-dihydropyridines: in vitro evaluation and structure-activity relationship study. Bioorg Med Chem. 2010;18(22): 8044-8053.

10. Sirisha K, Achaiah G, Reddy VM. Facile synthesis and antibacterial, antitubercular, and anticancer activities of novel 1,4-dihydropyridines. Arch Pharm (Weinheim). 2010;343(6):342-352.

11. Zorniak M, Mitrega K, Krzeminski TF. [Derivatives of 1,4-dihydropyridines as "priviledged structures" and their pharmacological potential] Kardiol Pol. 2011;69(suppl 3):100-103. Polish.

12. Marciniec B, Ogrodowczyk M. Photo- and radiostability of some 1,4dihydropyridine derivatives in the solid state. Acta Pol Pharm. 2003; 60(2):151-155.

13. Zhang D, Flint O, Wang L, et al. Cytochrome P450 11A1 bioactivation of a kinase inhibitor in rats: use of radioprofiling, modulation of metabolism, and adrenocortical cell lines to evaluate adrenal toxicity. Chem Res Toxicol. 2012;25(3):556-571.

14. Miri R, Javidnia K, Amirghofran Z, et al. Cytotoxic effect of some 1, 4-dihydropyridine derivatives containing nitroimidazole moiety. Iran J Pharm Res. 2011;10(3):497-503.

15. Niemirowicz K, Piktel E, Wilczewska AZ, et al. Core-shell magnetic nanoparticles display synergistic antibacterial effects against Pseudomonas aeruginosa and Staphylococcus aureus when combined with cathelicidin LL-37 or selected ceragenins. Int J Nanomedicine. 2016;11:5443-5455.
16. Niemirowicz K, Durnaś B, Tokajuk G, et al. Magnetic nanoparticles as a drug delivery system that enhance fungicidal activity of polyene antibiotics. Nanomedicine. 2016;12(8):2395-2404.

17. Taylor E, Webster TJ. Reducing infections through nanotechnology and nanoparticles. Int J Nanomedicine. 2011;6:1463-1473.

18. Niemirowicz K, Durnaś B, Piktel E, Bucki R. Development of antifungal therapies using nanomaterials. Nanomedicine (Lond). 2017;12(15): 1891-1905.

19. Kidd TJ, Mills G, Sá-Pessoa J, et al. A Klebsiella pneumoniae antibiotic resistance mechanism that subdues host defences and promotes virulence. EMBO Mol Med. 2017;9(4):430-447.

20. Logan LK, Weinstein RA. The epidemiology of carbapenem-resistant enterobacteriaceae: the impact and evolution of a global menace. J Infect Dis. 2017;215(supp1_1):S28-S36.

21. Massart R. Preparation of aqueous magnetic liquids in alkaline and acidic media. IEEE Trans Magn. 1981;17(2):1247-1248.

22. Niemirowicz K, Swiecicka I, Wilczewska AZ, et al. Gold-functionalized magnetic nanoparticles restrict growth of Pseudomonas aeruginosa. Int J Nanomedicine. 2014;9:2217-2224.

23. Meletiadis J, Mouton JW, Meis JF, et al. Comparison of spectrophotometric and visual readings of NCCLS method and evaluation of a colorimetric method based on reduction of a soluble tetrazolium salt, 2,3-bis [2-methoxy-4-nitro-5-[(sulfenylamino) carbonyl]-2H-tetrazoliumhydroxide], for antifungal susceptibility testing of Aspergillus species. J Clin Microbiol. 2001;39(12):4256-4263.

24. Yao Y, Ohko Y, Sekiguchi Y, Fujishima A, Kubota Y. Self-sterilization using silicone catheters coated with $\mathrm{Ag}$ and $\mathrm{TiO} 2$ nanocomposite thin film. J Biomed Mater Res B Appl Biomater. 2008;85(2):453-460.

25. Hussein-Al-Ali SH, El Zowalaty ME, Hussein MZ, Ismail M, Webster TJ. Synthesis, characterization, controlled release, and antibacterial studies of a novel streptomycin chitosan magnetic nanoantibiotic. Int J Nanomedicine. 2014;9:549-557.

26. Niemirowicz K, Durnaś B, Tokajuk G, et al. Formulation and candidacidal activity of magnetic nanoparticles coated with cathelicidin LL-37 and ceragenin CSA-13. Sci Rep. 2017;7(1):4610.

27. Sridhar J, Kuriyan AE, Flynn HW, Miller D. Endophthalmitis caused by Pseudomonas aeruginosa: clinical features, antibiotic susceptibilities, and treatment outcomes. Retina. 2015;35(6):1101-1106.

28. Barreras US, Méndez FT, Martínez RE, Valencia CS, Rodríguez PR, Rodríguez JP. Chitosan nanoparticles enhance the antibacterial activity of chlorhexidine in collagen membranes used for periapical guided tissue regeneration. Mater Sci Eng C Mater Biol Appl. 2016;58:1182-1187.

29. Feliciani C, Gupta AK, Sauder DN. Keratinocytes and cytokine/growth factors. Crit Rev Oral Biol Med. 1996;7(4):300-318.

30. Gloire G, Legrand-Poels S, Piette J. NF-kappaB activation by reactive oxygen species: fifteen years later. Biochem Pharmacol. 2006;72(11): $1493-1505$.

31. Davies J, Davies D. Origins and evolution of antibiotic resistance. Microbiol Mol Biol Rev. 2010;74(3):417-433.

32. Katz AM, Leach NM. Differential effects of 1,4-dihydropyridine calcium channel blockers: therapeutic implications. J Clin Pharmacol. 1987; 27(11):825-834.

33. Vijesh AM, Isloor AM, Peethambar SK, Shivananda KN, Arulmoli T, Isloor NA. Hantzsch reaction: synthesis and characterization of some new 1,4-dihydropyridine derivatives as potent antimicrobial and antioxidant agents. Eur J Med Chem. 2011;46(11):5591-5597.

34. Briede J, Stivrina M, Vigante B, Stoldere D, Duburs G. Acute effect of antidiabetic 1,4-dihydropyridine compound cerebrocrast on cardiac function and glucose metabolism in the isolated, perfused normal rat heart. Cell Biochem Funct. 2008;26(2):238-245.

35. Núñez-Vergara LJ, Squella JA, Bollo-Dragnic S, et al. Nitro aryl 1,4-dihydropyridine derivatives: effects on Trypanosoma cruzi. Comp Biochem Physiol C Pharmacol Toxicol Endocrinol. 1997;118(1): 105-111.

36. Sirisha K, Bikshapathi D, Achaiah G, Reddy VM. Synthesis, antibacterial and antimycobacterial activities of some new 4-aryl/heteroaryl-2,6dimethyl-3,5-bis-N-(aryl)-carbamoyl-1,4-dihydropyridines. Eur J Med Chem. 2011;46(5):1564-1571. 
37. Chhillar AK, Arya P, Mukherjee C, et al. Microwave-assisted synthesis of antimicrobial dihydropyridines and tetrahydropyrimidin-2-ones: novel compounds against aspergillosis. Bioorg Med Chem. 2006; 14(4):973-981.

38. Tasaka S, Ohmori H, Gomi N, et al. Synthesis and structure - activity analysis of novel dihydropyridine derivatives to overcome multidrug resistance. Bioorg Med Chem Lett. 2001;11(2):275-277.

39. Miri R, Mehdipour A. Dihydropyridines and atypical MDR: a novel perspective of designing general reversal agents for both typical and atypical MDR. Bioorg Med Chem. 2008;16(18):8329-8334.

40. Hetzel D, Strauss W, Bernard K, Li Z, Urboniene A, Allen LF. A phase III, randomized, open-label trial of ferumoxytol compared with iron sucrose for the treatment of iron deficiency anemia in patients with a history of unsatisfactory oral iron therapy. Am J Hematol. 2014;89(6): 646-650.

41. Niemirowicz K, Markiewicz KH, Wilczewska AZ, Car H. Magnetic nanoparticles as new diagnostic tools in medicine. Adv Med Sci. 2012; 57(2):196-207.

42. Piktel E, Niemirowicz K, Wątek M, Wollny T, Deptuła P, Bucki R. Recent insights in nanotechnology-based drugs and formulations designed for effective anti-cancer therapy. J Nanobiotechnology. 2016;14(1):39.
43. Azam A, Ahmed AS, Oves M, Khan MS, Habib SS, Memic A. Antimicrobial activity of metal oxide nanoparticles against Gram-positive and Gram-negative bacteria: a comparative study. Int J Nanomedicine. 2012;7:6003-6009.

44. Leuba KD, Durmus NG, Taylor EN, Webster TJ. Short communication: carboxylate functionalized superparamagnetic iron oxide nanoparticles (SPION) for the reduction of $S$. aureus growth post biofilm formation. Int J Nanomedicine. 2013;8:731-736.

45. Akbarzadeh T, Fallah Tafti A, Samadi N, et al. Synthesis and cloxacillin antimicrobial enhancement of 2-methylsulfonylimidazolyl-1,4dihydropyridine derivatives. Daru. 2010;18(2):118-123.

46. Bucki R, Janmey P. Extracellular aggregation of polyelectrolytes escaped from the cell interior: mechanisms and physiological consequences. Curr Opin Colloid Interface Sci. 2016;26:84-89.

47. Cieśluk M, Piktel E, Wątek M, et al. Neutrophil extracellular traps as the main source of eDNA. Med Stud. 2017;33(2):137-145.

48. Ruden S, Hilpert K, Berditsch M, Wadhwani P, Ulrich AS. Synergistic interaction between silver nanoparticles and membrane-permeabilizing antimicrobial peptides. Antimicrob Agents Chemother. 2009;53(8): $3538-3540$
International Journal of Nanomedicine

\section{Publish your work in this journal}

The International Journal of Nanomedicine is an international, peerreviewed journal focusing on the application of nanotechnology in diagnostics, therapeutics, and drug delivery systems throughout the biomedical field. This journal is indexed on PubMed Central, MedLine, CAS, SciSearch ${ }^{\circledR}$, Current Contents ${ }^{\circledR} /$ Clinical Medicine,

\section{Dovepress}

Journal Citation Reports/Science Edition, EMBase, Scopus and the Elsevier Bibliographic databases. The manuscript management system is completely online and includes a very quick and fair peer-review system, which is all easy to use. Visit http://www.dovepress.com/ testimonials.php to read real quotes from published authors. 